\title{
Ann Arbor Stage IIIE
}

National Cancer Institute

\section{Source}

National Cancer Institute. Ann Arbor Stage IIIE. NCI Thesaurus. Code C150549.

An Ann Arbor classification lymphoma stage term that refers to extralymphatic organ or site involvement plus involvement of lymph nodes on both sides of the diaphragm. 